\title{
Preoperative Tracheoscopy for Esophageal Atresia and/or Congenital Esoaerian Fistula: Experience at Cliniques Universitaires Saint Luc in Brussels
}

\author{
Natacha Boumas ${ }^{1 *}$, Beelke D'Hondt ${ }^{2}$, Catherine De Magnee ${ }^{2}$, Raymond Reding2, \\ Francis Veyckemans ${ }^{2}$ \\ ${ }^{1}$ Surgery Paediatric Unit, Centre Hospitalo universitaire Mère Enfant Jeanne Ebori, Libreville, Gabon \\ ${ }^{2}$ Surgery Unit and Paediatric Transplantation, Cliniques Universitaires Saint-Luc, Université Catholique de Louvain, Brussels, \\ Belgium \\ Email:^natacha_boumas@yahoo.fr
}

How to cite this paper: Boumas, N., D’Hondt, B., De Magnee, C., Reding, R. and Veyckemans, F. (2020) Preoperative Tracheoscopy for Esophageal Atresia and/or Congenital Esoaerian Fistula: Experience at Cliniques Universitaires Saint Luc in Brussels. Surgical Science, 11, 9-14. https://doi.org/10.4236/ss.2020.111002

Received: December 18, 2019

Accepted: January 11, 2020

Published: January 14, 2020

Copyright (C) 2020 by author(s) and Scientific Research Publishing Inc. This work is licensed under the Creative Commons Attribution International License (CC BY 4.0).

http://creativecommons.org/licenses/by/4.0/

\section{(c) (i) Open Access}

\begin{abstract}
Introduction: Congenital septal anomalies between the trachea and the esophagus are rare conditions. It seemed to us interesting to recall the contribution of tracheoscopy in the diagnostic and therapeutic strategy of esophageal atresia and congenital esoaerian fistulas. Patients and methods: This is a retrospective study between June 1994 and June 2014 of children who underwent a tracheoscopy, at the Saint-Luc University Clinics in Brussels, the diagnostic set of esophageal atresia (EA) or a congenital esoaerian fistula was suspected. Results: A total of 43 children with esophageal atresia or congenital esoaerian fistula underwent tracheoscopy. Before the tracheoscopy, the diagnosis of the anatomical type of atresia of the esophagus and esoaerian fistula was as follows: type C, 34 (79.1\%); type A, 4 (9.3\%); type E, 5 (11.6\%). After performing the tracheoscopy, the diagnosis was changed as follows: type $C$, 34 (79.1\%); type A, 3 (7\%); type E, 4 (9.3\%); type B, 1 (2.3\%), a patient with a tracheoesophageal laryngo cleft (2.3\%). Tracheoscopy also made it possible to find 2 cases of tracheomalacia, 2 cases with 3 bronchial tubes and one case associating a diverticulum of the trachea. No complications were correlated with the performance of the tracheoscopy. Conclusion: Our study confirms the benefits of tracheoscopy in the laden price of esophageal atresia or congenital esoaerian fistula.
\end{abstract}

\section{Keywords}

Esophageal Atresia, Esotracheal Fistula, Tracheobronchoscopy 


\section{Introduction}

Preoperative tracheobroncoscopy (TBS) in the diagnostic evaluation of newborns with esophageal atresia was described in 1981 [1], more than 30 years ago. However, the value of this procedure is in fact much debated [2]. Only a few studies have clearly explored the benefits of tracheobronchoscopy. This procedure is therefore not yet systematically included in the diagnostic and therapeutic evaluation in several pediatric surgery centers [2]. The role of routine preoperative TBS in esophageal atresia (EA) patients remains a matter of debate [2], with only $43 \%$ $60 \%$ of contemporary paediatric surgeons routinely using preoperative TBS in this setting [3] [4]. Advocates cite preoperative TBS findings which may impact management in $21 \%$ - $45 \%$ of EA patients, most notably unusual fistula position and tracheobronchial tree anomalies, and less commonly laryngeal clefts or subglottic stenosis [5] [6]. Preoperative TBS allows the precise examination of the tracheobronchial tree, the visualization of the eso-tracheal fistula(s), the diagnosis of tracheomalacia and the search for associated respiratory anomalies. The aim of our work was to assess the benefits and risks of performing preoperative TBS in newborns with esophageal atresia or congenital esoaerian fistula.

\section{Patients and Methods}

This is a retrospective study carried out at the Saint Luc University Clinics in Brussels over a period from June 1994 to June 2014. Children who underwent a tracheoscopy when diagnosed with esophageal atresia (EA) or congenital esoaerian fistula ("H" sotracheal (ETF), diastema or cleft laryngo tracheoesophageal) were suspected, were identified. Data collection was made from reports of hospitalisations and accounts of various consultations services and the operating records of the children concerned. We have analysed data from 43 patients. The parameters studied were: sex, birth term, birth weight, any associated malformations, type EA before TBS, preoperative tracheoscopy results, type EA post TBS and post TBS complications. Statistically, the data analysis was performed using SPSS software. The significance used for the tests was 0.05 .

A rigid bronchoscope (OD $1.9 \mathrm{~mm}, \mathrm{~K}$. Storz, Germany) was introduced into the trachea just before the surgical treatment. Induction was by inhalation of sevoflurane with oxygen, combined with local anesthesia (lidocaine) of the oropharyngeal, laryngeal and tracheal mucosa. During this procedure, the child was kept in spontaneous ventilation. The bronchoscope was connected to a camera to allow the surgeon and anesthesiologist to share the operator's findings.

When a FOT was found, it was catheterized by a Fogarty balloon catheter allowing its occlusion. After endoscopy, endotracheal intubation and positioning of the endotracheal tube were dependent on the outcome of the endoscopy to allow ventilation without gastric distention.

The parameters studied were sex, term of birth, birth weight, associated congenital anomalies, diagnosis of the pre-TBS anatomical type of esophageal atresia and esoaerian fistula, post-TBS diagnosis, modification from the surgical approach, the other anomalies of the tracheobronchial tree and the complications 
due to the realization of TBS.

\section{Results}

A total of 43 children (24 girls, 19 boys) with esophageal atresia or congenital esoaerian fistula underwent a 20-year tracheoscopy at the Cliniques Universitaires Saint Luc in Brussels. During this period, 60 children were identified as having esophageal atresia. Thus, the frequency of use was $71.6 \%$. The mean term of birth was 35 weeks of amenorrhea (WA) and 6 days with extremes of 25 and 40 WA. The average birth weight was $2452.4 \mathrm{~g}$ (range 410 - $3970 \mathrm{~g}$ ). Associated abnormalities were present in 20 patients.

Before the tracheoscopy, the diagnosis of the anatomical type of esophageal atresia and esoaerian fistula was as follows: type C, 34 (79.1\%); type A, 4 (9.3\%); type E, 5 (11.6\%). After performing the tracheoscopy, the diagnosis was changed as follows: C, 34 (79.1\%); type A, 3 (7\%); type E, 4 (9.3\%); type B, 1 (2.3\%); a patient with a tracheoesophageal laryngo cleft $(2.3 \%)$.

In the 34 patients with esophageal type $\mathrm{C}$ atresia, the tracheoscopy confirmed the diagnosis. The fistula was located at the level of the hull (Figure 1) in 9 newborns, in the lower half of the trachea in 24 newborns (ranging from 1 to $4 \mathrm{~cm}$ above the hull) and in the middle of the trachea in 1 new born.

In the 4 cases where an " $H$ " fistula (type E) was suspected, the tracheoscopy confirmed the diagnosis. After cannulation of the ETF (Figure 2), the first approach for the surgical treatment for EA type E was a cervicotomy (3 cases) and a thoracotomy (1 case) due to the location of the ETF opposite D3.

Tracheoscopy revealed other anomalies of the tracheobronchial tree: 2 cases of tracheomalacia; 2 cases with 3 stem bronchi and one case associating a diverticulum of the trachea.

No complications were correlated with the performance of the tracheoscopy.

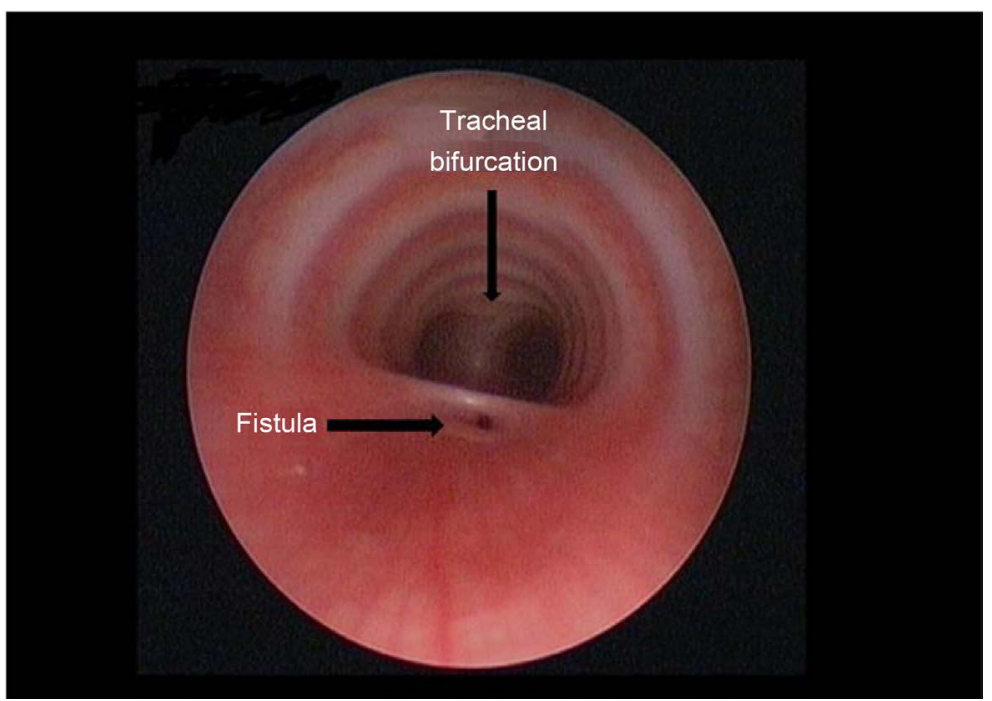

Figure 1. Laryngotracheobronchoscopy showing tracheoesophageal carinal fistula. 


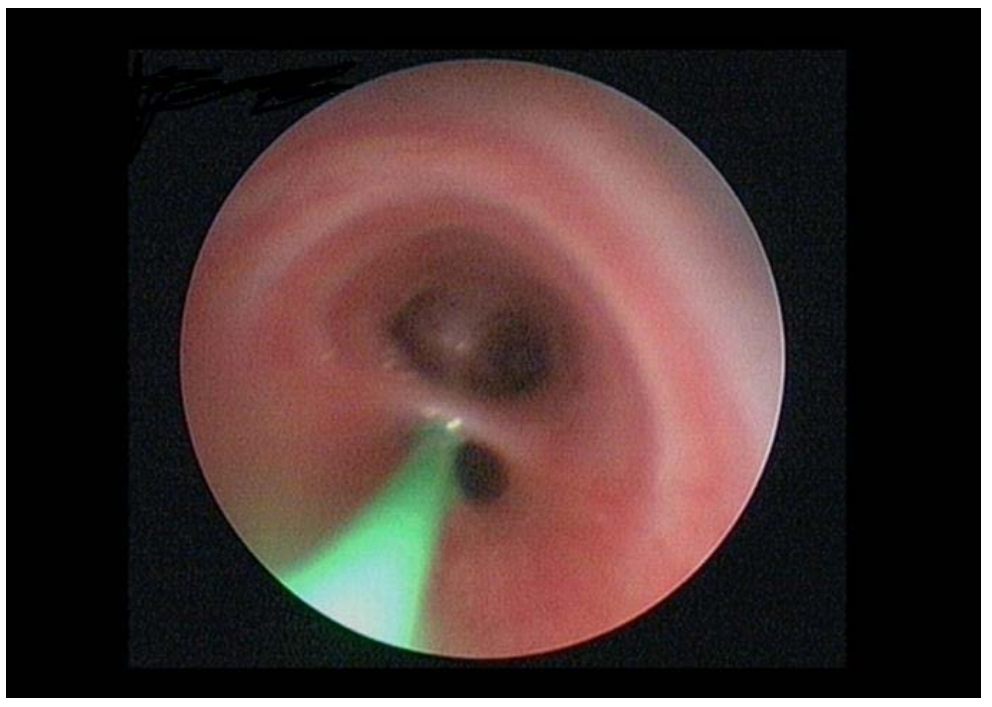

Figure 2. Tracheoscopic view of cannulated wide carinal fistula with Fogarty catheter.

\section{Discussion}

There are few data on the use of TBS as well as on the diagnostic evaluation and operative management of newborns with esophageal atresia [2]. The frequency of use in our series was $71.6 \%$. A survey of all members of the International Pediatric Endoscopy Group (IPEG) in 2012 was completed by 170 surgeons from 31 countries [3]. Only $60 \%$ of them underwent a tracheoscopy before the surgical repair [3]. A lower utilization rate has been found in other series, notably in Italy (40.5\%) and in France (21.5\%) [4] [7].

In our series, TBS confirmed the preoperative diagnosis of all type $\mathrm{C}$ and type E esophageal atresia. Our results are comparable to those of Atzori [5]. TBS can also be useful for the detection of associated malformations of the tracheobronchial tree. We found cases of tracheomalacia, 3 stem bronchi and a diverticulum of the trachea. The association of tracheomalacia and esophageal atresia has been well described, although often not detected [8]. According to Benjamin [1], the definitive diagnosis of tracheomalacia can be made by bronchoscopy. Kosloske et al. [9] concluded that tracheomalacia would be better assessed after repair of esophageal atresia and tracheoesophageal fistula in spontaneous respiration. The presence of significant tracheomalacia may alert clinicians to the need for non-invasive support following extubation. The benefit of preoperative TBS is maximal in newborns with suspected pure EA due to a "gasless abdomen" on x-ray. In this EA subgroup, TBS reveals a proximal ETF in 20\% - 33\% with resultant change in management [6] [10]. Preoperative endoscopic intubation of the ETF with the aim facilitating surgical repair, Fogarty balloon TOF occlusion to aid ventilation and selective trans-tracheal gastric drainage have been described [2] [5] [11] [12]. The surgical approach was modified in a patient with type E EA who underwent a thoracotomy due to the location of the ETF next to D3. Atzori et al. changed their surgical approach in $24.2 \%$ [5]. Thus, TBS was beneficial from 
a diagnostic point of view (anatomical type of EA and associated malformations) and therapeutic management in 7 patients. Also, cannulation of the fistula made it easier to identify the fistula during the thoracotomy. Oxygen desaturation, coughing, epistaxis, laryngospasm and bronchospasm have been the complications associated with the achievement of TBS described in very low birth weight infants [13] [14] [15]. Complications such as pneumothorax have been reported in children [6]. In our series, we did not find its complications. The limits of our study are the retrospective, monocentric and the operator expertise (TBS).

\section{Conclusion}

TBS is a useful and safe procedure. Our study confirms the benefits of TBS in the management of esophageal atresia or congenital esoaerian fistula. It facilitates surgical repair and improves ventilation of the newborn.

\section{Conflicts of Interest}

The authors declare no conflicts of interest regarding the publication of this paper.

\section{References}

[1] Benjamin, B. (1981) Endoscopy in Esophageal Atresia and Tracheo-Esophageal Fistula. Annals of Otology, Rhinology \& Laryngology, 90, 376-382. https://doi.org/10.1177/000348948109000418

[2] Parolini, F., Boroni, G., Stefini, S., et al. (2014) Role of Preoperative Tracheobronchoscopy in Newborns with Esophageal Atresia: A Review. World Journal of Gastrointestinal Endoscopy, 6, 482-487. https://doi.org/10.4253/wjge.v6.i10.482

[3] Lal, D., Miyano, G., Juang, D., Sharp, N.E. and St Peter, S.D. (2013) Current Patterns of Practice and Technique in the Repair of Esophageal Atresia and Tracheoesophageal Fistua: An IPEG Survey. Journal of Laparoendoscopic \& Advanced Surgical Techniques $A$, 23, 635-638. https://doi.org/10.1089/lap.2013.0210

[4] Zani, A., Eaton, S., Hoellwarth, M.E., Puri, P., Tovar, J., Fasching, G., Bagolan, P., Lukac, M., Wijnen, R., Kuebler, J.F., Cecchetto, G., Rintala, R. and Pierro, A. (2014) International Survey on the Management of Esophageal Atresia. European Journal of Pediatric Surgery, 24, 3-8. https://doi.org/10.1055/s-0033-1350058

[5] Atzori, P., Iacobelli, B.D., Bottero, S., Spirydakis, J., Laviani, R., Trucchi, A., Braguglia, A. and Bagolan, P. (2006) Preoperative Tracheobronchoscopy in Newborns with Esophageal Atresia: Does It Matter? Journal of Pediatric Surgery, 41, 1054-1057. https://doi.org/10.1016/j.jpedsurg.2006.01.074

[6] Sharma, N. and Srinivas, M. (2014) Laryngotracheobronchoscopy Prior to Esophageal Atresia and Tracheoesophageal Fistula Repair-Its Use and Importance. Journal of Pediatric Surgery, 49, 367-369. https://doi.org/10.1016/j.jpedsurg.2013.09.009

[7] Sfeir, R., Bonnard, A., Khen-Dunlop, N., Auber, F., Gelas, T., Michaud, L., Podevin, G., Breton, A., Fouquet, V., Piolat, C., Lemelle, J.L., Petit, T., Lavrand, F., Becmeur, F., Polimerol, M.L., Michel, J.L., Elbaz, F., Habonimana, E., Allal, H., Lopez, E., Lardy, H., Morineau, M., Pelatan, C., Merrot, T., Delagausie, P., de Vries, P., Levard, G., Buisson, P., Sapin, E., Jaby, O., Borderon, C., Weil, D., Gueiss, S., Aubert, 
D., Echaieb, A., Fourcade, L., Breaud, J., Laplace, C., Pouzac, M., Duhamel, A. and Gottrand, F. (2013) Esophageal Atresia: Data from a National Cohort. Journal of Pediatric Surgery, 48, 1664-1669.

https://doi.org/10.1016/j.jpedsurg.2013.03.075

[8] Montedonico, S., Diez-Pardo, J.A., Lassaletta, L., et al. (1999) Respiratory Malformations Associated with Esophageal Atresia. Cirugia Pediatrica, 12, 61-64.

[9] Kosloske, A.M., Jewell, P.F. and Cartwright, K.C. (1988) Crucial Bronchoscopic Findings in Esophageal Atresia and Tracheoesophageal Fistula. Journal of Pediatric Surgery, 23, 466-470. https://doi.org/10.1016/S0022-3468(88)80450-0

[10] Parolini, F., Morandi, A., Macchini, F., Canazza, L., Torricelli, M., Zanini, A. and Leva, E. (2013) Esophageal Atresia with Proximal Tracheoesophageal Fistula: A Missed Diagnosis. Journal of Pediatric Surgery, 48, E13-E17. https://doi.org/10.1016/j.jpedsurg.2013.04.018

[11] Pigna, A., Gentili, A., Landuzzi, V., Lima, M. and Baroncini, S. (2002) Bronchoscopy in Newbornswith Esophageal Atresia. La Pediatria Medica e Chirurgica, 24, 297-301.

[12] Deanovic, D., Gerber, A.C., Dodge-Khatami, A., Dillier, C.M., Meuli, M. and Weiss, M. (2007) Tracheoscopy Assisted Repair of Tracheo-Esophageal Fistula (TARTEF): A 10-Year Experience. Pediatric Anesthesia, 17, 557-562. https://doi.org/10.1111/j.1460-9592.2006.02147.x

[13] De Blic, J., Marchac, V. and Scheinmann, P. (2002) Complications of Flexible Bronchoscopy in Children: Prospective Study in 1328 Procedures. European Respiratory Journal, 20, 1271-1276. https://doi.org/10.1183/09031936.02.02072001

[14] Nussbaum, E. (2002) Pediatric Fiberoptic Bronchoscopy: Clinical Experience with 2.836 Bronchoscopies. Pediatric Critical Care Medicine, 3, 171-176. https://doi.org/10.1097/00130478-200204000-00015

[15] Scellhase, D.E., Graham, L.M., Fix, E.J., et al. (1990) Diagnosis of Tracheal Injury in Mechanically Ventilated Premature Infants by Flexible Bronchoscopy. A Pilot Study. Chest, 98, 1219-1225. https://doi.org/10.1378/chest.98.5.1219 